\title{
BMJ Global Health Intergenerational transfer of health inequalities: exploration of mechanisms in the Birth to Twenty cohort in South Africa
}

\author{
Dieter von Fintel, ${ }^{\oplus 1}$ Linda Richter ${ }^{\odot} 2$
}

To cite: von Fintel D, Richter L. Intergenerational transfer of health inequalities: exploration of mechanisms in the Birth to Twenty cohort in South Africa. BMJ Global Health 2019;4:e001828. doi:10.1136/ bmjgh-2019-001828

Handling editor Seye Abimbola

Received 9 July 2019

Revised 22 August 2019

Accepted 30 August 2019

\section{Check for updates}

C Author(s) (or their employer(s)) 2019. Re-use permitted under CC BY-NC. No commercial re-use. See rights and permissions. Published by BMJ.

${ }^{1}$ Economics, Stellenbosch University, Stellenbosch, South Africa

${ }^{2}$ Centre of Excellence in Human Development, University of the Witwatersrand, Johannesburg, South Africa

Correspondence to Professor Dieter von Fintel; dieter2@sun.ac.za

\section{ABSTRACT}

South Africa's history of colonialism and Apartheid contributed to its extreme levels of inequality. Twentyfive years after the transition to democracy, socio-economic and health inequalities continue to rank among the highest in the world. The Birth to Twenty+ study follows a cohort born in urban Johannesburg in 1990 through their early lives and into young adulthood. Also known as 'Mandela's Children', these 'children of the ' $90 \mathrm{~s}$ ' were the first generation to be raised in a democratic society, whose elected government implemented policies to achieve greater socio-economic and health equality. Correlating early life outcomes to those of their parents provides a baseline estimate of intergenerational transmission of historical inequality. Analyses of their early life course indicates the potential breakdown in inequality in the first generation. This paper provides an overview of empirical results on intergenerational change in socio-economic status and health during South Africa's political transition. Access to infrastructural services improved, and poverty reduced following the rapid expansion of unconditional cash transfers mainly to children and pensioners. However, unemployment remained high and job discrimination continued. Inequalities in health follow similar patterns, and progress did not equate to convergence. Some catch-up physical growth occurred - both across groups and over time-but not sufficient to bridge cognitive inequalities. Socio-economic and health inequalities continued as the children of the ' 90 s reached young adulthood. Based on knowledge of other transitions, it is likely that these inequalities will only start to break down in later generations, provided social and economic progress holds steady.

\section{INTRODUCTION}

South Africa is among the most unequal countries in the world. In 2018, it ranked 113 of 189 countries on the Human Development Index. Poverty and unemployment are high, and life expectancy is estimated at 63.4 years. ${ }^{1}$ Like many very unequal countries, South Africa has low levels of intergenerational change in incomes, with children earning very much what their parents did. ${ }^{2}$ There
Summary box

- The Birth to Twenty+ (Bt20+) prospective longitudinal birth cohort tracks the first generation of young people raised in democratic South Africa, allowing for an empirical view of changes in socio-economic and health status in response to social and political shifts.

- The baseline in 1990 shows that children inherited economic and health inequalities from their parents who lived under the discriminatory policies of the Apartheid state.

- Twenty-five years after democracy, the socio-economic and health status of people in South Africa has improved, but outcomes remain strongly constrained by the conditions under which the previous generation lived.

- Addressing disparities that are inherited from birth takes time, possibly two to three generations, depending on the how equitably opportunities, access and quality of services are provided.

is also wide variation in health outcomes ${ }^{3}$ and educational inequality persists mainly through the poor quality of historically disadvantaged schools. ${ }^{4}$ While the average level of education of South Africans has increased since the mid-1990s, ${ }^{5}$ it is not associated with proportional increases in earnings at the lower ends of the educational continuum. Only high school completion and tertiary education show increased income returns to education. ${ }^{67}$ As Finn et $a l^{7}$ state 'If the starting point of each generation is highly unequal, and the transmission of economic outcomes from parents to children largely deterministic, then this has clear implications for the persistence of inequality in society' (p6).

\section{A PROSPECTIVE BIRTH COHORT STUDY INITIATED AT THE TIME OF POLITICAL TRANSITION}

Rising resistance to Apartheid, the policy of separate and unequal treatment of Black 
people in South Africa, came to the boil in the 1980s, particularly in the densely populated economic hub on the Witwatersrand, including Johannesburg and Soweto. The Abolition of the Influx Control Act of 1986, which reversed only one of many pieces of inter-related legislation that controlled the movement, living and working conditions of Black people, symbolised the tangible beginning of the breakdown of the Apartheid state.

The free movement of people led to rapid urbanisation from a relatively low level, particularly among Black people. It was anticipated to compound existing problems in urban areas, including lack of employment, inadequate housing, poor services, rising crime, long commuting distances and disrupted family life. ${ }^{8}$ Among other initiatives to better understand and prepare for changing health patterns and service needs with increasing urbanisation, scientists at the South African Medical Research Council and the University of the Witwatersrand established a birth cohort to study the impact of the anticipated political, economic, nutritional and health transitions.

The Birth to Twenty+ (B20+) cohort study, dubbed 'Mandela's Children' and 'children of the 90s', included all children born in the 6 weeks following 23 April 1990 within the municipal boundaries of Soweto and Johannesburg. Of the 5449 singleton births in the recruitment window, 3273 mothers and their children remained resident in the area 6 months after delivery and constitute the cohort. The aim was to study physical, psychological, social and educational aspects of the children's development in the context of their socio-economic and family conditions in an intensive prospective longitudinal design. Various forms of attrition, including mortality, mobility and circular migration affect sample sizes during data collection rounds ${ }^{9}$

The sample breakdown by Apartheid race classifications reflects the population as a whole: most children were black African children (79\%) who were historically disadvantaged by the Apartheid regime, with a relatively small proportion of Whites $(6 \%)$ who were historically privileged. ${ }^{10}$ Now aged 29 years, participants have been assessed on human development indicators 22 times, generally on an annual cycle, with a larger gap between 22 and 28 years. ${ }^{1112}$

The study provides a baseline for urban children's biological, environmental, socio-economic and psychosocial experiences on the eve of South Africa's democratic transition. It represents a unique source from which to examine whether the extreme disadvantages experienced by adults living under Apartheid continued to the first generation growing up under a democratic dispensation. The period was marked by significant political, economic and social changes; by all expectations, socio-economic gaps (across areas, social classes and race groups that were separated by Apartheid laws) should have narrowed. This paper summarises selected evidence that assessed whether societal shifts also reflected in improved socio-economic and health indicators across generations-those born at the dawn of democracy, and their parents who were born during Apartheid. The discussion focuses on the correspondence between secular socio-economic improvements and the (slow) change experienced by a young generation of Africans to reach a position beyond that of their disadvantaged parents.

\section{HAVE SOCIO-ECONOMIC AND HEALTH GAPS NARROWED?}

South Africa's first democratically elected government followed a multi-pronged agenda to tackle the country's glaring socio-economic disparities. The approach ranged from investment in infrastructure to direct welfare initiatives. In 1994, the Reconstruction and Development Programme was adopted with the aim of creating a developmental state. ${ }^{13}$ South African government spending prioritises human development. Adjusting for inflation, per person public expenditure on health, schooling and social development has doubled in the two decades after Apartheid, and is the largest component of the national budget. ${ }^{14}$ Primary healthcare and primary schooling are provided without charge to the most vulnerable groups, and feeding programmes are widespread in poor schools. Most notably, more than 17 million poor South Africans receive unconditional cash transfers (approximately 30\% of the population). These spending patterns rank South Africa as one of the most redistributive emerging economies. Despite the scale of social policy in monetary terms, inequality and poverty remain high relative to comparative countries (including Brazil). ${ }^{15}$ In addition, access to housing, water, sanitation and electricity has expanded dramatically-in many cases with subsidies towards the poor. A 'headline' view suggests that, at least in part, the programmes have been successful.

The prevalence of poverty-measured as households' command over minimum levels of expendituredeclined in the early 2000s. The trend is attributed mainly to the rapid expansion of unconditional government cash transfers (for children, pensioners and people living with disabilities).${ }^{16}$ The programme is one of the largest of its kind in a middle-income country, and has brought about marginal improvements along a range of socio-economic dimensions, including the linear growth of children and their progress through education. ${ }^{17}$ Among other benefits, the programme contributed to narrowing large spatial differences in self-reported hunger across former Apartheid homelands (areas to which the majority Black population were confined) and the rest of the country. ${ }^{18}$ However, these positive trends were not sustained. By 2015 official poverty rates started to rise again. About half of the population can now be described as 'chronically poor', never having escaped poverty at any point in time. ${ }^{19}$

In addition to social programmes that protect basic levels of consumption, public provision of housing, electricity, piped water and sanitation have expanded at large scale. Rural areas, with very low levels of provision, experienced greater improvement. ${ }^{20}$ For instance, only $26.5 \%$ 
of rural households had access to electricity for lighting in 1993, increasing to $65 \%$ in the first decade of democracy. Expansion of access to piped water occurred almost exclusively in rural areas. However, despite reductions in these disparities, historic separate development policies are still strongly evident in current socio-economic indicators. ${ }^{21}$ The changes brought about progress but not convergence.

Labour market conditions remain a key constraint to bridging socio-economic gaps. Non-discriminatory access to well-paying jobs is a precondition for alleviating inequalities and creating equality of opportunity. Yet, the economic environment has not changed in a manner to support these outcomes. Many South Africans-especially the younger generation-continue to be isolated from jobs that generate incomes necessary to climb the economic ladder. ${ }^{22}$ Even for those who find work, the playing field remains imbalanced. Despite legislated affirmative action, there is little evidence to suggest that racial discrimination has decreased in the work place, except among the very rich. ${ }^{23}$ Access to secure jobsboth in terms of permanence and adequate pay-is an essential precursor to creating stability for South Africa's middle-class. ${ }^{24}$ However, many South Africans find it difficult to hold onto well-paid work, leaving them economically vulnerable. Upward economic mobility is therefore often temporary. Consequently, socio-economic disparities continue, with limited intergenerational income mobility. ${ }^{2}$ Despite significant social and economic changes, the World Bank describes South Africa's experience as an 'incomplete transition'. ${ }^{25}$

Other life outcomes closely mirror the unequal socio-economic conditions that exist between people, groups and areas. While under-five mortality dropped gradually between 1990 and 2015 and life expectancy has risen thanks to the provision of antiretroviral treatment for HIV patients, childhood stunting has remained high over the long run. Where improvements have occurred, they have been concentrated among the poorest, who typically have the worst nutrition and are under-served in the health system. ${ }^{26-28}$ However, access to healthcare continues to be strongly correlated with socio-economic status, despite the democratic constitution's commitment to universal care. ${ }^{29}$ Wealthier individuals mainly access high quality private care paid by medical insurance through their employment, while poorer individuals rely on public services, often over-burdened and with inadequate resources. Racial imbalances in employment entail that White individuals are more likely than Black individuals to access private insurance and high quality care; consequently, the burden of disease is also more concentrated among the latter group. ${ }^{30}$

Because access to services is limited by socio-economic constraints, it is unsurprising that outcomes associated with healthcare follow the same pattern. To understand these gaps, we turn to evidence derived from a number of studies that use data from Bt20+. The study participants come from an urban setting, and therefore the findings cannot detect urban-rural disparities. Nevertheless, significant variation in socio-economic status within this group sheds light how it affects human development, including health.

In 1990, birth weight did not differ significantly by socio-economic category, although conditions of delivery did. Better off women were more likely to deliver their babies in a private facility and to have a Caesarean section delivery. ${ }^{31}$ In the early years, the physical growth of socio-economic groups diverged, creating substantial early life inequalities. ${ }^{32}$ At age 5 , children from higher socio-economic status households were at par with international height benchmarks and heavier than weight benchmarks; in contrast, poorer children continued to fall below these thresholds. Even though all socio-economic groups grew heavier for their age by age 5 , growth since birth was more substantial among the best-off children. Children who already lived in better conditions grew faster, even if social and health policies were aimed to benefit the poorest.

This socio-economic divergence also reflects in different experiences across Apartheid race classifications. White and Black African children had similar birth weights and heights up to 1 year of age. But White children grew better across childhood and adolescence, following unequal trajectories expected under Apartheid but not during democracy. ${ }^{10}$ Nonetheless, comparisons with data from an earlier study, ${ }^{33}$ show that African children from the $\mathrm{Bt} 20+$ cohort were taller on average, at the same ages, than those born and raised before democracy. ${ }^{10}$ No similar generational shifts occurred within the privileged White population, and this contributed to narrowing the gap. Alternative data sources confirm that there was a (slight) narrowing of the large and persistent racial gap in adult heights, even before democracy. ${ }^{34}$ Overall, as with other socio-economic indicators, there has been some progress across generations-this is partially attributed to a shift towards high energy diets among urban Africans. ${ }^{10}$ However, the political transition has not yet eliminated anthropometric inequalities across socio-economic and race groups.

\section{ARE CHILDREN'S OUTCOMES TIED TO THE DISADVANTAGES FACED BY THEIR PARENTS?}

There are some indications of biological and socio-economic improvements in the lives of younger generations from poorer backgrounds. However, with younger generations still having the highest unemployment rates over and above usual life cycle disadvantages, ${ }^{22}$ it stands to reason they are still-to varying degrees-tied to the disadvantages experienced by older generations who grew up during the Apartheid era, though these links may be weakening.

To better understand this, we explore evidence from two separate phases of human development. First, we consider whether there are direct associations between parent's (especially mother's) conditions and those of 
their children at birth. This sets the 'baseline' for likely transfers of disadvantages across generations. Second, we follow children to understand how strongly early life experiences continue to be correlated with outcomes across childhood and adolescence. This describes the potential leeway for children to break free of disadvantages that they inherit from their parents.

\section{Links between mothers and children}

A recent study correlated the physical stature of mothers and children across four countries (Brazil, India, Philippines and the Bt20+ cohort in South Africa). ${ }^{35}$ In all regions, maternal heights are strongly associated with their children's weight at birth. However, the link does not stop there: maternal height continues to be strongly related to child height at age 2 . This pattern remains after accounting for the contribution that intermediate events and circumstances made towards children's stature. Others have also found that heights are strongly persistent over generations. ${ }^{36}$ Both the environment and inherited traits of parents play a role in child height. For instance, in three countries, socio-economic status has a relationship with height at age 2 that is as strong as the intergenerational pathway, indicating that improved economic conditions in the home can offset generational persistence. The exception is South Africa, where socio-economic conditions do not play as large a role as maternal height in determining early child growth (The weak links may also be the result of the relatively lower variation in socio-economic conditions in the poor urban South African sample compared with other countries.). ${ }^{35}$ As matters stand, there is no strong evidence to suggest that societal change could counter intergenerational disadvantage in the early 1990s in South Africa, at least in children's growth. This conclusion is bolstered by a review which found that South Africa's rates of stunting (compromised child length or height) have not changed in the 40 years since $1970 .^{27}$

Mother's mental health before and after pregnancy also affects children in multiple ways. For example, Bt20+ children were more likely to be stunted and exhibit behavioural problems at age 2 if their mothers experienced postnatal depression. ${ }^{37}$ This link may not be systematically 'intergenerational' or causal; rather, postnatal depression and child behaviour might both be temporary, and not necessarily tie children permanently to parental disadvantage. However, evidence from another study in South Africa at another point in the life cycle found that the most important predictor of adolescent depression is whether parents also suffer from these symptoms-one third of adolescents with depressed parents are also depressed. ${ }^{38}$ The relationship is, however, considerably weaker when households receive cash transfers. These two studies suggest that mental health may be linked across generations, but that socio-economic intervention can weaken the tie.

\section{Links between early and later life}

Early socio-economic and anthropometric gapseither inherited or which result from difficult early life circumstances-can transfer to other domains later in life. Should these conditions persist, the case for 'strong ties' to the disadvantage of previous generations remains convincing. However, where the ties deteriorate or where interventions have effect, it indicates that children can take a different path to their parents.

Studies of various low and middle-income countries (which include Bt20+) shed light on these competing hypotheses. On the one hand, mother's heights are correlated with their offspring's growth at various life phases, continuing as far as early adulthood ${ }^{39}$ and the subsequent generation of children. ${ }^{40}$ This pattern supports the 'strong ties' hypothesis, whereby inherited attributes rather than post-natal environmental changes or interventions (such as nutrition) determine lifetime physical growth. On the other hand, life trajectories can change. A combination of growth in the first 2 years of life and improvements in socio-economic conditions significantly altered educational outcomes. ${ }^{41}$ Children are therefore not necessarily bound by their parent's experiences; changes in socio-economic conditions, and the context of expanding public provision of education in democratic South Africa, are associated with better schooling attainments. While improved early life growth does not necessarily occur because of political and economic transitions, children who grew quicker were more likely to also experience the benefits of secular societal shifts. Children with poorer parents therefore experienced relatively larger changes in schooling, showing generational progress.

Improved schooling attainment does not necessarily mean that high quality results have followed. Bt20+ children who had compromised linear growth at age 2 years, that is they were stunted, performed worse on cognitive tests before entering the school system (at age 4 or 5). ${ }^{42}$ This pertained even after taking socio-economic differences into account. Catch up physical growth in subsequent years did not lessen the cognitive difference. ${ }^{43}$ Children who were never stunted continued to have higher cognitive scores at age 5 compared with those who were stunted early in life, even when they experienced substantial catch-up in their heights at a later stage. Height (dis)advantages at very early critical phases of development are therefore strongly correlated with inequality in later cognitive function, and the latter differences are difficult to alleviate because skill acquisition is cumulative. ${ }^{44}$ The correlations do not necessarily break down over the early life course, and this includes the salient times of political transition.

Psychosocial disadvantages may be more amenable to change. Preschool children's psychosocial health in Bt20+ was found to be unrelated to their early life growth. ${ }^{42}$ Children's emotional and social capacity were therefore not as constrained by their early life experiences as cognitive development. These observations concur with evidence from other countries. ${ }^{44}$ The foundations for cognitive skills are laid very early in life and are difficult to change, but even teenagers can be helped 
to strengthen their non-cognitive skills (or psychosocial health) to catch up to their peers.

Despite the potential to bridge non-cognitive gaps, socio-economic conditions can continue to constrain children's psychosocial health. At age 6, hyperactivity, immaturity and relational difficulties were all more severe among Bt20 +children living in poverty. ${ }^{45}$ In addition, these children were less likely to be resilient, affable and ready for school. ${ }^{46}$ These associations may be the result of the social context at the time. The early 1990s was characterised by social instability-especially in Johannesburg, where parts of the city experienced factional political violence in the run-up to the first democratic elections. Poor children lived in areas where community safety was compromised. Both financial insecurity and concerns for physical safety can have consequences for children's emotional well-being and their preparedness to adapt to their social surroundings.

\section{CONCLUSION}

At the verge of democracy in 1990, South Africans had high expectations for political and social change. While headline indicators show that socio-economic conditions improved, the changes have not been far-reaching enough to eliminate gaps across socio-economic and racial groups. Improved access to services, infrastructure and cash transfers correlate with significant reductions in poverty and improvements in health. The Bt20+ data provides a unique lens to track this first generation from birth into adulthood. Results show that the "children of the '90s' have seen significant improvements in a range of biological and psychosocial indicators in the context of socio-economic change; nevertheless, they inherit biological and social inequalities from their parents. While some of these inequalities declined in parallel with improvements in socio-economic conditions, groups did not converge. Poor urban children grew taller after adopting new diets, but did not keep pace with wealthier children; poor children have more education than their disadvantaged parents-and especially those who followed favourable physical development paths in early childhood. Policies to expand access to education have profoundly changed younger generations' opportunities to learn. However, gaps remain which leave the $\mathrm{Bt} 20+$ similar to the generation that lived under the Apartheid state. Even poor children who grew quicker in early life, did not necessarily achieve the same cognitive function that other privileged children did-and this despite improvements in access to schooling. Continuing gaps in the quality of schooling by socio-economic status may be one policy bottleneck to prioritise ${ }^{4}$; however, knowing that cognitive skills develop cumulatively over the life course,${ }^{44}$ progress across generations will rely on renewed focus on Early Childhood Development initiatives in the critical window of the first 1000 days of life. Each of these factors could, in turn, contribute to fairer employment possibilities across race and socio-economic groups. Following the Bt20+ cohort into later stages of adulthood, a time when participants become more independent from their parents, will reveal whether they will be free in their lifetime from the disadvantages suffered by their parents. However, like epigenetic changes, it is likely that social inequalities may take two to three generations to be eliminated, provided favourable environmental conditions prevail. ${ }^{47}$ A great deal hinges on South Africa being able to keep social and economic progress steady.

Acknowledgements The authors would like to thank workshop participants at the KNAW workshop at Erasmus Rotterdam Medical Centre, seminar participants at Stellenbosch University and collaborators for their comments on this work. We are also greatful for the suggestions of the editor and three anonymous reviewers. Errors and opinions remain those of the authors.

Contributors DvF conceptualised the idea, wrote and reviewed the article. LR wrote and reviewed the article.

Funding This study was funded by DST-NRF Centre of Excellence in Human Development.

\section{Competing interests None declared.}

Patient consent for publication Not required.

Ethics approval University of Witwatersrand Human Research Ethics Committee (Medical) Application Number M1811136. Stellenbosch University Human Research Ethics Committee Reference numberREC-2018-6639.

Provenance and peer review Not commissioned; externally peer reviewed.

Data availability statement № data are available.

Open access This is an open access article distributed in accordance with the Creative Commons Attribution Non Commercial (CC BY-NC 4.0) license, which permits others to distribute, remix, adapt, build upon this work non-commercially, and license their derivative works on different terms, provided the original work is properly cited, appropriate credit is given, any changes made indicated, and the use is non-commercial. See: http://creativecommons.org/licenses/by-nc/4.0/.

\section{REFERENCES}

1. United Nations Development Programme. Human development indices and indicators. Hum Dev Indices Indic 2018 http://www.hdr. undp.org/en/2018-update (accessed 9 Jul 2019).

2. Piraino P. Intergenerational earnings mobility and equality of opportunity in South Africa. World Dev 2015;67:396-405.

3. Ataguba JE-O, Alaba O. Explaining health inequalities in South Africa: a political economy perspective. Dev South Afr 2012;29:756-64.

4. van der Berg S. Apartheid's enduring legacy: inequalities in education. J Afr Econ 2007;16:849-80.

5. Lam D, Finn A, Leibbrandt M. Schooling inequality, returns to schooling, and earnings inequality: evidence from Brazil and South Africa. Helsinki: United Nations University - WIDER, 2015.

6. Moll PG. The collapse of primary schooling returns in South Africa 1960-90. Oxf Bull Econ Stat 1996;58:185-209.

7. Finn A, Leibbrandt M, Ranchhod V. Patterns of persistence: intergenerational mobility and education in South Africa. Cape Town: University of Cape Town, 2016. http://localhost:8080/ handle/11090/828. (accessed 9 Jul 2019).

8. van der Merwe IJ. A geographical profile of the South African population as a basis for epidemiological cancer research. S Afr Med J 1988;74:513-8.

9. Norris SA, Richter LM, Fleetwood SA. Panel studies in developing countries: case analysis of sample attrition over the past 16 years within the birth to twenty cohort in Johannesburg, South Africa. J Int Dev 2007;19:1143-50.

10. Cameron N. Physical growth in a transitional economy: the aftermath of South African apartheid. Economics Human Biology 2003;1:29-42.

11. Yach D, Cameron N, Padayachee N, et al. Birth to ten: child health in South Africa in the 1990s. rationale and methods of a birth cohort study. Paediatr Perinat Epidemiol 1991;5:211-33. 
12. Richter LM, Yach D, Cameron N, et al. Enrolment into birth to ten (BTT): population and sample characteristics. Paediatr Perinat Epidemiol 1995;9:109-20.

13. Blumenfeld J. From icon to scapegoat: the experience of South Africa's reconstruction and development programme. Dev Policy Rev 1997;15:65-91.

14. National Treasury. National Treasury. Natl Budg Rev Repub South Afr 2019.

15. Inchauste $\mathrm{G}$, Lustig N, Maboshe $\mathrm{M}$, et al. The Distributional impact of fiscal policy in South Africa. World Bank Policy Res Work Pap 2015:7194

16. van der berg servaas, louw megan, yu derek, et al. Post-Transition poverty trends based on an alternative data source. South African $J$ Economics 2008;76:58-76.

17. Coetzee M. Finding the benefits: estimating the impact of the South African child support grant. South Afr J Econ 2013.

18. Pienaar $L$, von Fintel $D$. Hunger in the former apartheid homelands: determinants of convergence one century after the 1913 land act. Agrekon 2014;53:38-67.

19. Zizzamia R, Schotte S, Leibbrandt M. Snakes and ladders and loaded dice: poverty dynamics and inequality in South Africa between 2008-2017. Cape Town: University of Cape Town, 2019. http://localhost:8080/handle/11090/950. (accessed 9 Jul 2019).

20. Bhorat $\mathrm{H}$, van der Westhuizen $\mathrm{C}$. Non-monetary dimensions of wellbeing in South Africa, 1993-2004: a post-apartheid dividend? Dev South Afr 2013;30:295-314.

21. Burger R, van der Berg S, van der Walt $S$, et al. The long walk: considering the enduring spatial and racial dimensions of deprivation two decades after the fall of apartheid. Soc Indic Res 2017;130:1101-23.

22. Burger R, von Fintel DP. Rising unemployment in a growing economy: a business cycle, generational and life cycle perspective of post-transition South Africa's labour market. Stud Econ Econom 2014;30:35-64.

23. Burger R, Jafta R, et al. Affirmative action in South Africa: an empirical assessment of the impact on labour market outcomes. In: Steward F, Langer A, Venugopal R, et al, eds. Affirmative Action in Plural Societies - International Experiences. Basingstoke: Palgrave: 80-99. https://www.palgrave.com/gp/book/9780230277809. (accessed 9 Jul 2019).

24. Schotte S, Zizzamia R, Leibbrandt M. A poverty dynamics approach to social stratification: the South African case. World Dev 2018;110:88-103.

25. World Bank. South Africa - Systematic country diagnostic : an incomplete transition - overcoming the legacy of exclusion in South Africa. Washington D.C: The World Bank, 2018. http:// documents.worldbank.org/curated/en/815401525706928690/SouthAfrica-Systematic-country-diagnostic-an-incomplete-transitionovercoming-the-legacy-of-exclusion-in-South-Africa

26. Bamford LJ, McKerrow NH, Barron P, et al. Child mortality in South Africa: fewer deaths, but better data are needed. S Afr Med J 2018;108:25.

27. Said-Mohamed R, Micklesfield LK, Pettifor JM, et al. Has the prevalence of stunting in South African children changed in 40 years? A systematic review. BMC Public Health 2015;15.

28. Mayosi BM, Benatar SR. Health and health care in South Africa 20 years after Mandela. N Engl J Med 2014;371:1344-53.
29. Harris B, Goudge J, Ataguba JE, et al. Inequities in access to health care in South Africa. J Public Health Policy 2011;32:S102-S123.

30. Burger R, Christian C. Access to health care in post-apartheid South Africa: availability, affordability, acceptability. Health Econ Policy Law 2018;X:1-13.

31. Ellison GT, Matshidze KP, Richter LM, et al. Medical aid and racial bias in caesarean section rates. S Afr Med J 1996;86:696-8.

32. Cameron N, De Wet T, Ellison GT, et al. Growth in height and weight of South African urban infants from birth to five years: the birth to ten study. Am. J. Hum. Biol. 1998;10:495-504.

33. Richardson BD. Growth patterns of South African children: an overview. S Afr Med J 1978;74:246-9.

34. Mpeta B, Fourie J, Inwood K. Black living standards in South Africa before democracy: new evidence from height. S Afr J Sci 2018;114:8

35. Richter LM, Orkin FM, Roman GD, et al. Comparative models of biological and social pathways to predict child growth through age 2 years from birth cohorts in Brazil, India, the Philippines, and South Africa. J Nutr 2018:1-8.

36. Stein $A D$, Wang M, Martorell $R$, et al. Growth patterns in early childhood and final attained stature: data from five birth cohorts from low- and middle-income countries. Am J Hum Biol 2010;22:353-9.

37. Avan B, Richter LM, Ramchandani PG, et al. Maternal postnata depression and children's growth and behaviour during the early years of life: exploring the interaction between physical and mental health. Arch Dis Child 2010:95:690-5.

38. Eyal K, Burns J. The parent trap: cash transfers and the intergenerational transmission of depressive symptoms in South Africa. World Dev 2019;117:211-29.

39. Addo OY, Stein AD, Fall $\mathrm{CH}$, et al. Maternal height and child growth patterns. J Pediatr 2013;163:549-54

40. Addo OY, Stein AD, Fall CHD, et al. Parental childhood growth and offspring birthweight: pooled analyses from four birth cohorts in low and middle income countries: parental childhood growth and offspring birthweight. Am J Hum Biol 2015;27:99-105.

41. Martorell R, Horta BL, Adair LS, et al. Weight gain in the first two years of life is an important predictor of schooling outcomes in pooled analyses from five birth cohorts from low- and middleincome countries. J Nutr 2010;140:348-54.

42. Casale D, Desmond C, Richter L. The association between stunting and psychosocial development among preschool children: a study using the South African birth to twenty cohort data. Child Care Health Dev 2014;40:900-10.

43. Casale D, Desmond C. Recovery from stunting and cognitive outcomes in young children: evidence from the South African birth to twenty cohort study. J Dev Orig Health Dis 2016;7:163-71.

44. Cunha F, Heckman J. The technology of skill formation. American Economic Review 2007;97:31-47.

45. Barbarin OA, Risks S. Social risks and psychological adjustment: a comparison of African American and South African children. Child Dev 1999;70:1348-59.

46. Barbarin OA, Richter L. Adversity and psychosocial competence of South African children. Am J Orthopsych 1999;69:319-27.

47. Kuzawa CW, Thayer ZM. Timescales of human adaptation: the role of epigenetic processes. Epigenomics 2011;3:221-34. 